OPEN ACCESS

Edited by:

Francisco Sanchez-Madrid,

Autonomous University of Madrid,

Spain

Reviewed by:

José Luis Rodríguez-Fernández, Consejo Superior de Investigaciones Cientificas (CSIC), Spain

Michael Sixt,

Institute of Science and Technology Austria (IST Austria), Austria

*Correspondence:

Evert J. Loef

e.j.loef@auckland.ac.nz

P. Rod Dunbar

r.dunbar@auckland.ac.nz

${ }^{\dagger}$ Deceased

Specialty section:

This article was submitted to

T Cell Biology,

a section of the journal

Frontiers in Immunology

Received: 11 November 2020

Accepted: 05 March 2021

Published: 26 March 2021

Citation:

Loef EJ, Sheppard HM, Birch NP and Dunbar PR (2021) Live-Cell Microscopy Reveals That Human

$T$ Cells Primarily Respond

Chemokinetically Within a

CCL19 Gradient That Induces

Chemotaxis in Dendritic Cells.

Front. Immunol. 12:628090. doi: 10.3389/fimmu.2021.628090

\section{Live-Cell Microscopy Reveals That Human T Cells Primarily Respond Chemokinetically Within a CCL19 Gradient That Induces Chemotaxis in Dendritic Cells}

\author{
Evert J. Loef ${ }^{1,2 *}$, Hilary M. Sheppard ${ }^{1,2}$, Nigel P. Birch ${ }^{1,3 \dagger}$ and P. Rod Dunbar ${ }^{1,2 *}$ \\ ${ }^{1}$ School of Biological Science, University of Auckland, Auckland, New Zealand, ${ }^{2}$ Maurice Wilkins Centre for Molecular \\ Biodiscovery, University of Auckland, Auckland, New Zealand, ${ }^{3}$ Centre for Brain Research and Brain Research New Zealand, \\ Rangahau Roro Aotearoa, University of Auckland, Auckland, New Zealand
}

The ability to study migratory behavior of immune cells is crucial to understanding the dynamic control of the immune system. Migration induced by chemokines is often assumed to be directional (chemotaxis), yet commonly used end-point migration assays are confounded by detecting increased cell migration that lacks directionality (chemokinesis). To distinguish between chemotaxis and chemokinesis we used the classic "under-agarose assay" in combination with video-microscopy to monitor migration of CCR7 + human monocyte-derived dendritic cells and T cells in response to a concentration gradient of CCL19. Formation of the gradients was visualized with a fluorescent marker and lasted several hours. Monocyte-derived dendritic cells migrated chemotactically towards the CCL19 gradient. In contrast, T cells exhibited a biased random walk that was largely driven by increased exploratory chemokinesis towards CCL19. This dominance of chemokinesis over chemotaxis in T cells is consistent with CCR7 ligation optimizing $T$ cell scanning of antigen-presenting cells in lymphoid tissues.

Keywords: cell migration, chemokines, CCR7, real-time microscopy, gradient formation, $\mathrm{T}$ cell and mDC co-culture

\section{INTRODUCTION}

Cell migration is a key process in a myriad of physiological functions (1). Homing of both $\mathrm{T}$ cells and dendritic cells to lymph nodes is largely dependent on activation of the chemokine receptor CCR7 (1). Co-localization of these cells within the $\mathrm{T}$ cell zones present in lymph nodes allows $\mathrm{T}$ cells to scan DCs for their cognate antigen, ultimately enabling activation and expansion of antigenspecific T cells (2). The CCR7 ligand CCL19 is considered to be strongly chemotactic for both T cells and dendritic cells (DCs), potentially driving their co-localization. However intra-vital microscopy in mice has revealed that migration of $\mathrm{T}$ cells within lymph nodes does not have strong features of directional chemotaxis (3). It has been suggested that the random directionality observed in vivo doesn't exclude the possibility that there is an underlying directional bias (4). Understanding how CCL19 might act through the same receptor to generate different types of migratory behavior in $\mathrm{T}$ cells and DCs is central to understanding the dynamic control of $\mathrm{T}$ cell responses. 
Data to support the concept that CCL19 drives chemotaxis for both T cells and DCs are often drawn from "transwell" assays that are based on the original Boyden assay (5). In these assays the cells and the chemotactic agent are separated by a membrane with pores large enough to permit cell migration; the number of cells that move from the cell chamber to the second chamber are counted. Given that the pores in the barriers are large enough to permit cell transit, it is likely that chemotactic agents applied to one chamber will rapidly equilibrate in the other chamber. Some researchers have modified these assays by coating the porous barriers with extracellular matrix, fibrin or collagen gels, and in some cases monolayers of endothelial or epithelial cells. Under these conditions, concentration gradients may be maintained for periods long enough to assess cell migration. However, these transwell assays are typically used as endpoint assays so crucial migratory information is not measurable, such as migration speed and track straightness toward the chemokine over time. The use of endpoint assays also introduces a confounding error in terms of measuring directional chemotaxis: agents that simply increase the speed of migration of cells, with no or very little directional component, will increase the number of cells detected in the second chamber, effectively reading out chemokinetic effects or biased random walks as chemotaxis.

The study presented here aimed to use a simple real-time migration assay that would allow for the detailed study of migration of human DCs and T cells in response to chemokines.

We used the "under-agarose" assay that was originally developed in 1975 by Simmons et al. (6). This assay allows the researcher to set up two (or more) competing chemoattractant signals whereby chemoattractants diffuse slowly through gels, rather than rapidly equilibrating in solution. The presence of a gel also allows for the study of cell movement in a confined plane, allowing for an integrin-independent amoeboid type of migration that mimics the major type of locomotion of DCs and T cells in 3D matrices, which is suggested to be better suited to rapidly follow chemotactic gradients (7-9). This assay, and other similar assays have been widely used to study the migration of cells (10-13). In this study, we used agar rather than agarose as this increased the number of migrating cells. The use of live-cell microscopy enabled the visualization of the migration of human monocyte-derived dendritic cells (mDCs) and human T cells in real-time. Because CCL19, unlike CCL21, is a soluble chemokine (14), Fluorescent dextrans of a similar size $(10 \mathrm{kDa})$ were used to demonstrate that a concentration gradient was generated that lasted for several hours. This provided sufficient time to allow for definitive tracking of cell migration paths over hundreds of microns in the presence of a CCL19 gradient or a uniform CCL19 concentration.

This method showed that human mDCs exhibit true chemotaxis toward a gradient of CCL19. Human polyclonal T cells, however, respond to a CCL19 gradient with a biased random walk, showing directional bias, but largely chemokinetic, and showing similarities to the response to a uniform CCL19 concentration. The strong chemokinetic response in $\mathrm{T}$ cells is consistent with efficient strategies to scan antigen-presenting cells for cognate antigen within lymphoid tissue.

\section{MATERIALS AND METHODS}

\section{Cell Culture}

All cytokines were purchased from Peprotech (Rocky Hill, NJ, USA). Human blood was obtained from healthy volunteers after informed consent and with approval by the University of Auckland Human Participant Ethics Committee (Ethics Approval 010558). Peripheral blood mononuclear cells were prepared using Lymphoprep (Axis-Shield, Dundee, Scotland) density gradient centrifugation. mDCs were differentiated from CD $14^{+}$monocytes based on a previously reported method (15). In short, $\mathrm{CD}_{1} 4^{+}$cells were isolated using the MACS human CD $14^{+}$isolation kit (Miltenyi Biotec, Bergisch Gladbach, Germany) according to the manufacturer's protocol. $1-2 \times 10^{6}$ $\mathrm{CD} 14^{+}$cells were plated in a 24 well plate with AIM-V medium (Life Technologies, Carlsbad, California, USA) supplemented with 1x GlutaMAX-I (Life Technologies) and $200 \mathrm{ng} \mathrm{mL} \mathrm{m}^{-1} \mathrm{IL}-4$ and $100 \mathrm{ng} \mathrm{mL}^{-1} \mathrm{GM}$-CMSF. Half of the medium was replaced at day 2 or 3. On day five non-adherent and mildly-adherent cells were resuspended and transferred to a $15 \mathrm{~mL}$ conical tube and centrifuged at $350 \mathrm{~g}$ for 5 minutes. The pellet was resuspended in

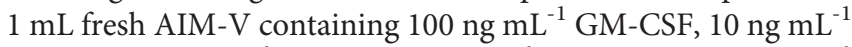
IL-1 $\beta, 100 \mathrm{ng} \mathrm{mL}^{-1} \mathrm{IL}-6,250 \mathrm{ng} \mathrm{mL}^{-1} \mathrm{TNF}-\mathrm{a}$ and $1 \mu \mathrm{g} \mathrm{mL} \mathrm{mL}^{-1}$ PGE2 to mature the cells for a further 48 hours. Expanded T cells, in this manuscript only referred to as T cells, were cultured in RPMI-1640 medium containing 5\% human serum (One Lambda, Los Angles, California, USA), $100 \mathrm{U} \mathrm{mL}^{-1}$ penicillin (Life Technologies), $100 \mu \mathrm{g} \mathrm{mL} \mathrm{m}^{-1}$ streptomycin (Life Technologies), and $2 \mathrm{mM}$ GlutaMAX-I (Life Technologies), supplemented with $5 \mathrm{ng} \mathrm{mL}^{-1}$ IL-7 (referred to as RS5-IL7) unless stated otherwise. T cells were polyclonally expanded from freshly isolated PBMCs using Dynabeads human T-activator CD3/CD28 beads (Life Technologies) as previously described (16-18). In brief, $10^{6}$ PBMCs were activated with Dynabeads at a bead:cell ratio of 1:1 for 3 days in RS5-IL7, supplemented with 10 ng $\mathrm{mL}^{-1} \mathrm{IL}-12$ and $10 \mathrm{ng} \mathrm{mL}^{-1} \mathrm{IL}-21$. Following magnetic removal of the beads, the cells were cultured for a further 4 days using the same medium, followed by 7 days in RS5-IL7 supplemented with IL-21. Cells were examined daily, and cultures were split once cells were confluent, or the medium showed signs of acidification (usually every 2-3 days). Cells were rested for a further 7-10 days in RS5-IL7 prior to use or cryopreservation. Cryopreserved $\mathrm{T}$ cells were allowed to recover for at least $24 \mathrm{~h}$ in RS5-IL7 (20 $\mathrm{ng} \mathrm{mL} \mathrm{m}^{-1}$ ) before use. Post recovery, every $\mathrm{T}$ cell expansion was tested for expression of CCR7 by flow cytometry (Supplementary Figure 1) and only T cell expansions that showed a more than $50 \% \mathrm{CCR}^{+}$population were used in experiments.

\section{Agar Set Up}

To make $0.5 \%$ agar gels, $2 \mathrm{~mL} 2 \mathrm{x}$ RPMI (made from powder) (Sigma St. Louis, Missouri, USA) was mixed with $200 \mu$ l human serum (One Lambda, Los Angles, California, USA) and $800 \mu \mathrm{l}$ ultrapure $\mathrm{H}_{2} \mathrm{O}$. This was prewarmed to $37^{\circ} \mathrm{C}$ in a water bath. $2 \%$ agar was dissolved in ultrapure $\mathrm{H}_{2} \mathrm{O}$ by bringing it to a boil in the microwave and mixing it on high speed on a vortex mixer for 20 
seconds. This process was repeated four times. One $\mathrm{mL}$ of the agar solution was added to the prewarmed mixture to make a $0.5 \%$ agar medium solution. Of the solution, $800 \mu \mathrm{l}$ was added to each well of a 4 well 1.5 polymer tissue culture treated chambered coverslip (Ibidi, Martinsried, Germany) that was precoated with $20 \%$ human serum in RPMI for $30 \mathrm{~min}$ at $37^{\circ} \mathrm{C}$. To generate a uniform concentration of CCL19 (PeproTech), CCL19 was

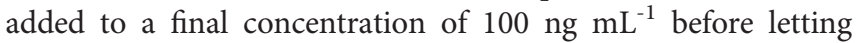
the agar solidify. The agar was left to set for 1 hour. Next, a threepronged bespoke autopsy punch was used to create a line of three wells, each of a three $\mathrm{mm}$ diameter and $2 \mathrm{~mm}$ apart in the agar (Supplementary Figure 2).

\section{Microscopy}

The cells were stained with Cytotrack green or red (Bio-Rad, Hercules, California, USA). The dye was diluted 1:500 in PBS. The cells were resuspended in the PBS dye solution at $2 \mathrm{M}$ cells $\mathrm{mL}^{-1}$ and incubated at room temperature for 15 minutes. Cells were then centrifuged at $350 \mathrm{~g}$ for $5 \mathrm{~min}$ and washed once with their respective culturing medium followed by resuspension in RPMI-1640 medium (Life Technologies) containing 5\% human serum (One Lambda, Los Angeles, CA, USA), $100 \mathrm{U} \mathrm{mL}^{-1}$ penicillin (Life Technologies), $100 \mu \mathrm{g} \mathrm{mL}^{-1}$ streptomycin (Life Technologies), and $2 \mathrm{mM}$ GlutaMAX-1 (Life Technologies), supplemented with $5 \mathrm{ng} \mathrm{mL} \mathrm{mL}^{-1} \mathrm{IL}-7$. The cells (100, $000 \mathrm{~T}$ cells, $50,000 \mathrm{mDCs}$ or $50,000 \mathrm{~T}$ cells and $25,000 \mathrm{mDCs}$ ) were added to the middle well in the agar set up. In one of the outside agar wells 100 ng CCL19 was added to generate a gradient by diffusion (Supplementary Figure 2A). In experiments where the diffusion was visualized, 100 ng Dextran, Texas Red, 10,000 MW, Neutral (Life Technologies) was added at the same time.

The $\mu$ slide containing the agar and cells was then placed on an inverted Nikon TI-e (Nikon, Tokyo, Japan) and visualized using a 10x 0.4 NA Nikon lens and an Andor Zyla 5.5 camera (Oxford Instruments, Abingdon, UK). An image was taken every minute for up to the indicated times.

\section{Image Analysis}

Imaris software (Oxford Instruments) was used to analyze the image sequences. Using the spot tracking module the cells were detected by their respective fluorescence label and tracked in 1-hour blocks.

\section{Statistics}

Prism 8.1.2 (GraphPad, San Diego, CA, USA) was used for all statistical analysis.

\section{RESULTS}

\section{Set Up and Gradient Generation in an Under-Agar Assay}

In the under-agar set up used in this study (Supplementary Figure 2) fluorescent dextrans of similar size to CCL19 ( 10 $\mathrm{kDa}$ ) were used to measure the "steepness" and duration of the gradient in real-time concurrent with the $\mathrm{mDC}$ response to CCL19 (Figure 1, Supplementary Video 1). Measuring the diffusion of the dextrans indicates that a steep gradient is formed after one hour and that the gradient persists for up to six hours (Figure 1B). By adding CCL19 at the same time as the fluorescent dextrans it was possible to analyze the response of mDCs to the visual gradient that was formed. At one-hour post addition of CCL19 and dextrans, a "wave" of mDCs migrating out of the well and going under the agar can be observed. This matches the visualized diffusion of the fluorescent dextrans, which reached the mDCs in the middle well in the agar at that time. The increased directional migration of the mDCs compared to the control condition lacking CCL19 (Supplementary Video 2) lasted for up to six hours, gradually getting less directional as the steepness of the gradient decreases over time, again matching the gradient as visualized by the dextrans. Analysis of cell movement highlights the difference in migration between cells that receive a CCL19 signal and those that do not. This allows the comparison of "classic" chemotaxis parameters such as the number of responding cells (Figure 1C), track straightness (Figure 1D), migration speed (Figure 1E), and the displacement in the $\mathrm{X}$ and $\mathrm{Y}$ direction of the cells (Figure 1F).

\section{Chemotaxis and Chemokinesis Can Be Clearly Distinguished Using Time-Lapse Imaging}

When our under-agar assay was used as an end-point assay, in the same way as the original under-agarose assay published in 1975 (6) we can see that with both a gradient of CCL19 and a uniform concentration, migration of $\mathrm{mDC}$ and $\mathrm{T}$ cells can be observed (Figure 2). When CCL19 was lacking, very little migration or almost no migration was observed for mDCs and $\mathrm{T}$ cells respectively. Even though the cell number appears to be visually higher when there is a gradient present for the mDCs, chemokinesis can easily be mistaken for chemotaxis in this type of analysis. We also noted that visually there seemed to be increased migration by $\mathrm{T}$ cells when co-incubated with $\mathrm{mDCs}$, suggesting some interaction between the cells or the tracks they make in the agar.

When comparing a gradient of CCL19 with a uniform concentration of CCL19 in real-time we observe clear differences in the way mDCs are migrating (Supplementary Videos 1 and 3). When the tracks are plotted from a single origin point we can see that mDCs display a clear chemotactic migration toward the CCL19 gradient compared to mDCs that have been exposed to a uniform CCL19 concentration (Figure 3). This $\mathrm{mDC}$ migration was unaffected by the presence of $\mathrm{T}$ cells during co-migration experiments (Figure 4). However, unlike mDCs, $\mathrm{T}$ cells do not show true chemotactic migration toward CCL19, either when migrating in the presence or absence of mDCs (Figure 4, Supplementary Videos 4-7).

When the number of tracks, track straightness, and track speed were plotted and compared over time, a clear difference can be observed when comparing mDCs responding to a CCL19 

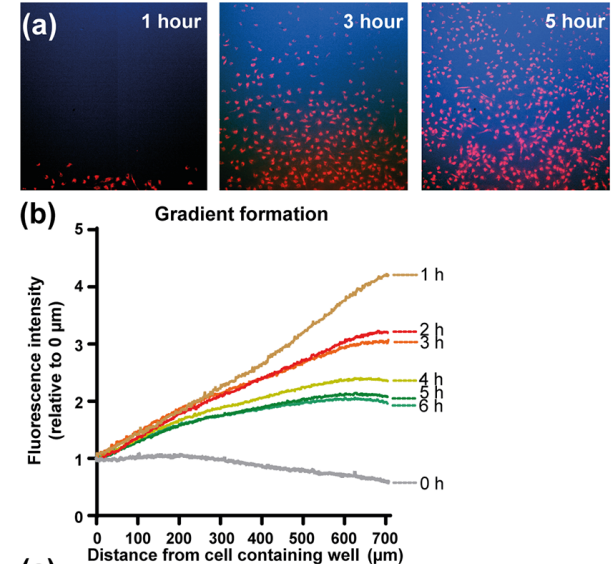

(c)

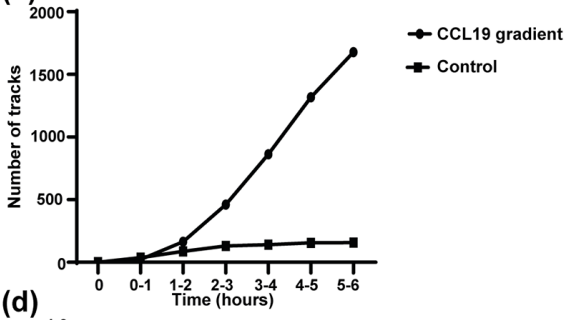

(d)

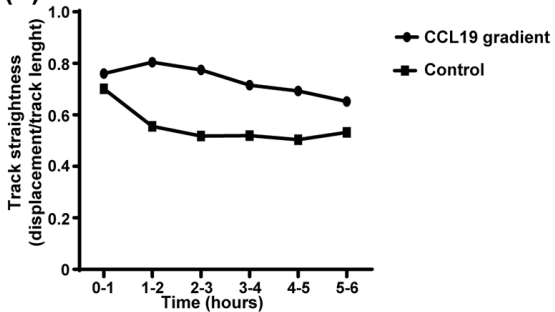

(e)

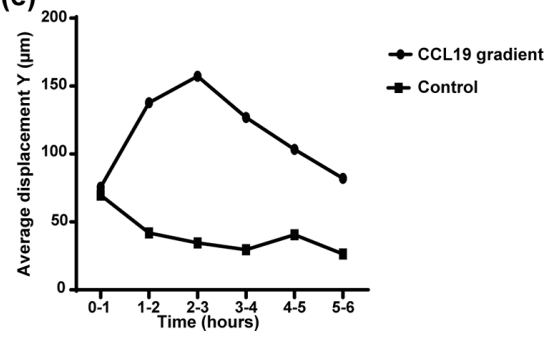

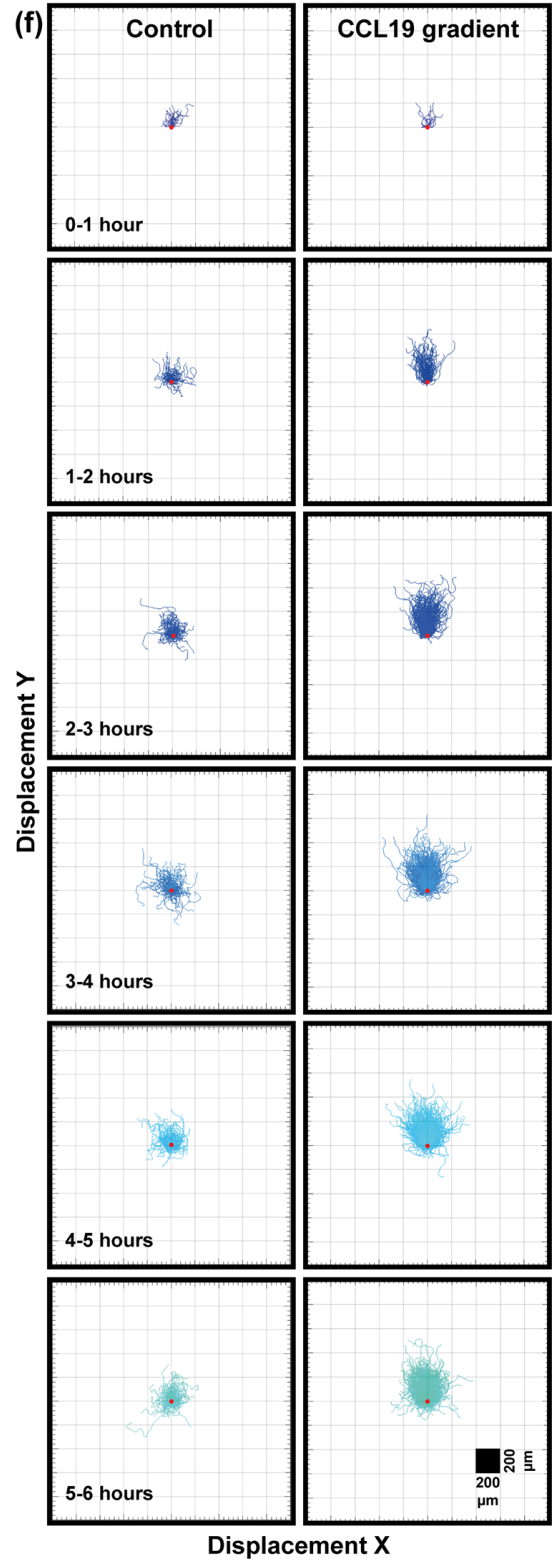

Displacement $\mathbf{X}$

FIGURE 1 | Dendritic cells respond chemotactically to a cytokine gradient in the "under-agar" assay, which lasts for several hours as shown by fluorescent dextrans. (A) Images showing the diffusion of fluorescent dextran (blue) a nd migration of mDCs (red) at one, three and five hours of incubation. (B) The formation of a gradient in the under-agar assay as shown by diffusion of $10 \mathrm{kDa}$ dextrans. (C) Graph showing the number of tracked mDCs over time in response to a CCL19 gradient or no chemokine (control). (D) Graph showing the track straightness of mDCs over time in response to a CCL19 gradient or no chemokine (control). (E) Graph showing the displacement of mDCs in the direction of the CCL19 gradient or in the same direction without chemokine (control). (F) "Spider plots" showing the tracks of mDCs over time in response to a CCL19 gradient or no chemokine (control) plotted from a single origin point (red dot). All data is from one representative experiment that was repeated at least three times.

gradient and a uniform CCL19 concentration (Figure 4A). Although there was an increase in the number of $\mathrm{mDCs}$ migrating in the absence of T cells with a CCL19 gradient, this was not statistically significant. The mDCs that are migrating do so in significantly straighter tracks when responding to the gradient. The track speed is similar between the two conditions, indicating that a gradient is less important for inducing migration but that it regulates the direction of the mDCs. $\mathrm{T}$ cells, on the other hand, show only minor differences in migration to a gradient or a uniform CCL19 concentration (Figure 4A). However, when the displacement was analyzed by subtracting the displacement of $\mathrm{T}$ cells in a uniform CCL19 concentration from the displacement of T cells in a CCL19 gradient there was an increase in displacement toward CCL19 (Figure 4B, solid line). 

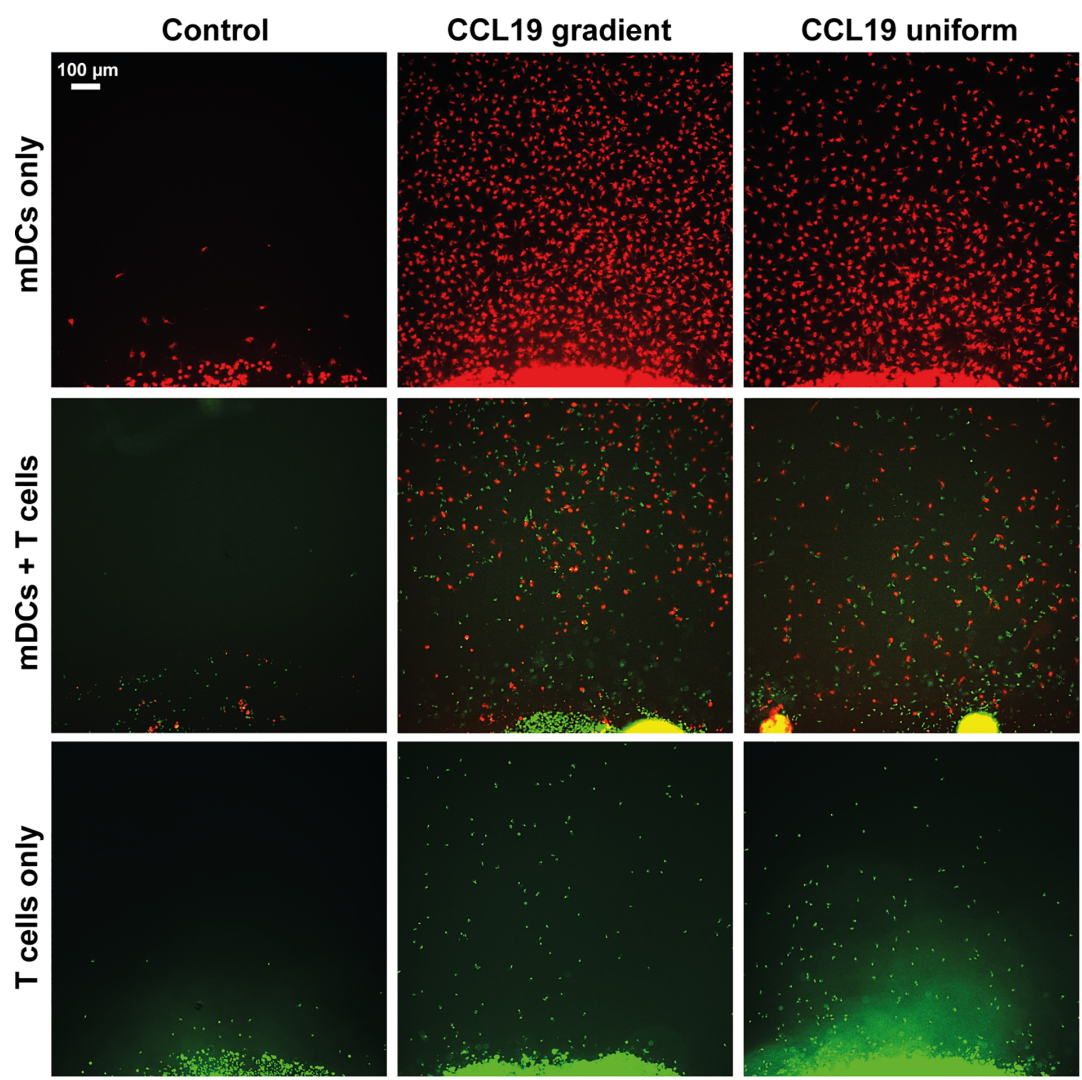

FIGURE 2 | Static assays do not clearly distinguish between chemotaxis and chemokinesis. Images showing migration after 16 hours of incubation of mDCs (red) and T cells (green) without chemokine (Control), in response to a CCL19 gradient, and $100 \mathrm{ng} \mathrm{mL}^{-1}$ uniform CCL19 concentration.

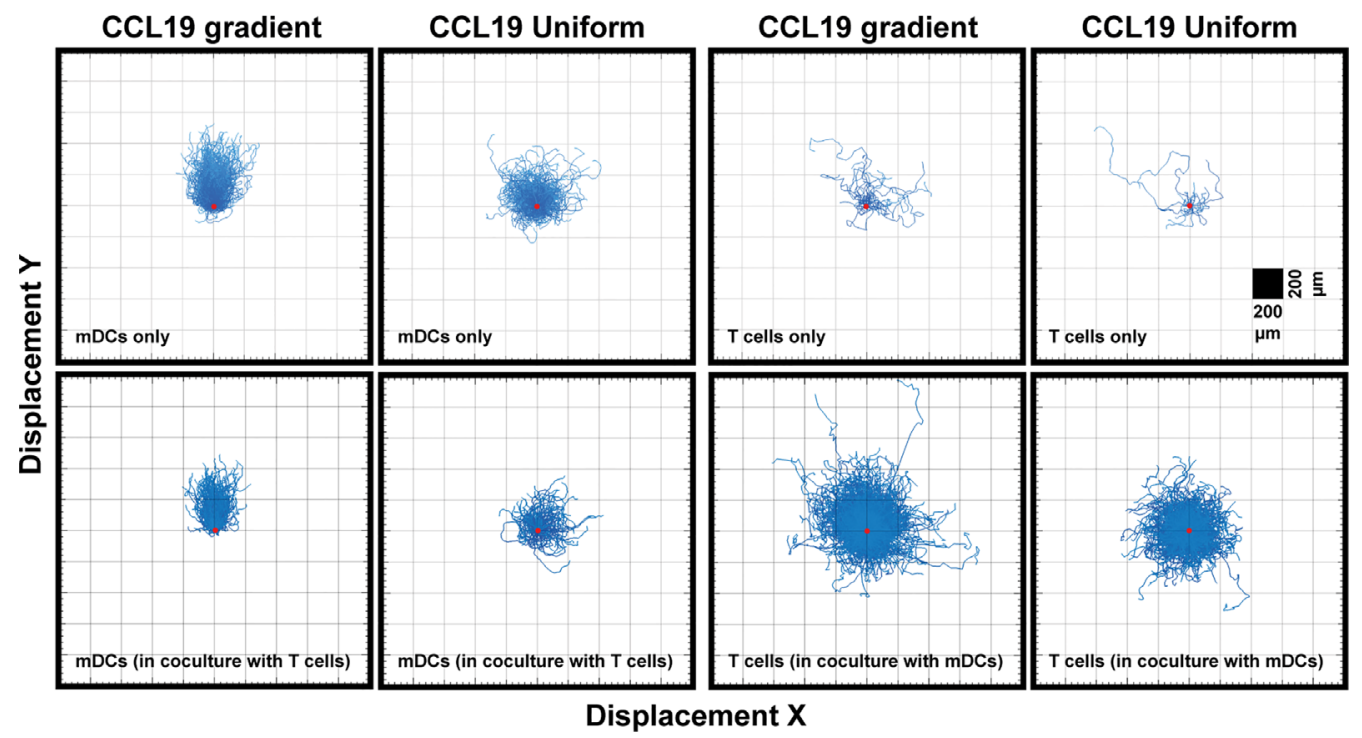

FIGURE 3 | Unlike DCs, T cells do not show a strong chemotactic response to a CCL19 gradient. "Spider plots" showing the tracks of mDCs and T cells over time in response to a CCL19 gradient or a uniform $100 \mathrm{ng} \mathrm{mL}^{-1} \mathrm{CCL} 19$ concentration plotted from a single origin point (red dot). All data is from one representative experiment that was repeated at least three times. 

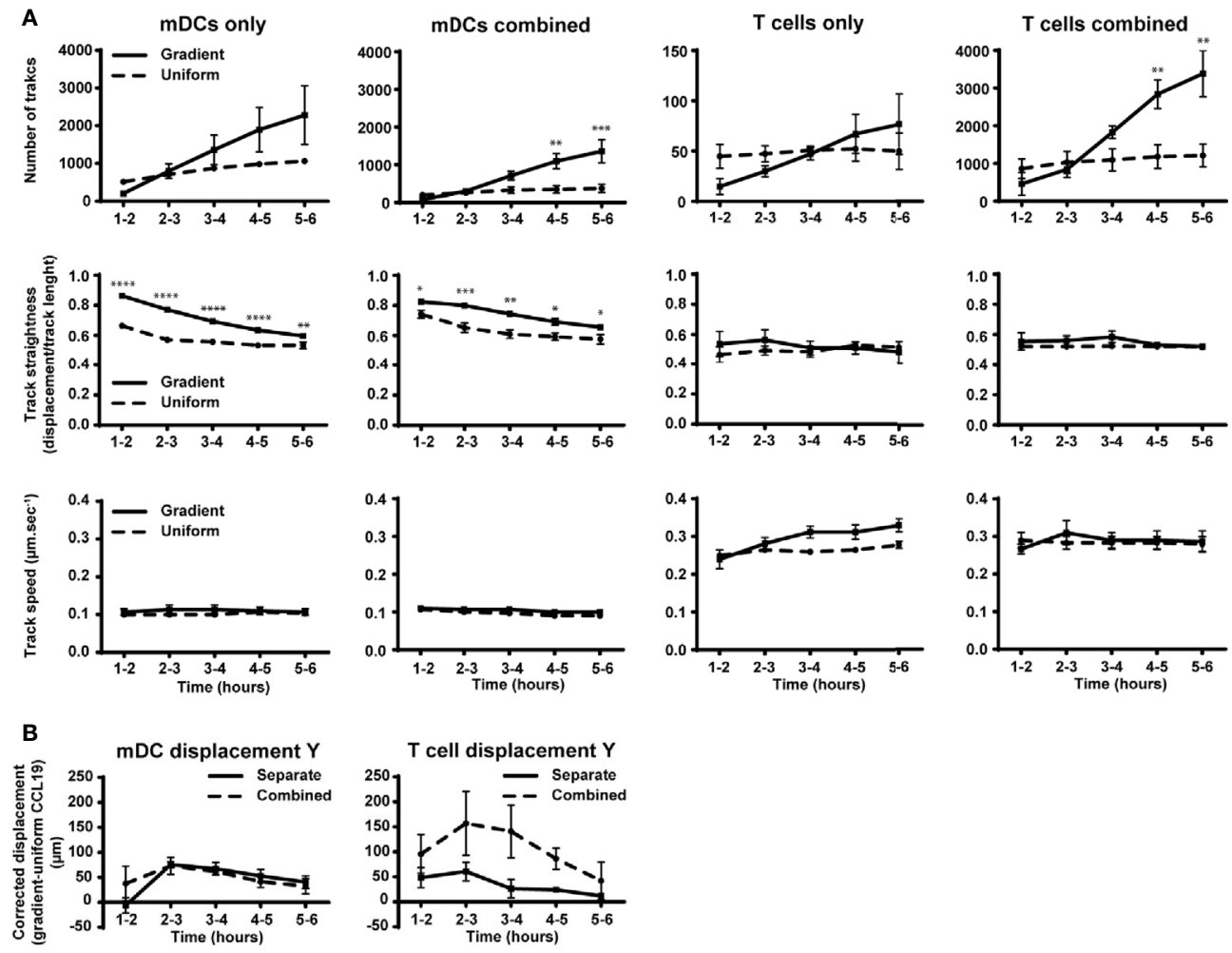

FIGURE 4 | Migration behavior of DCs is not altered by the presence of T cells while the number of T cells and their displacement toward CCL19 is increased in the presence of mDCs. (A) Graphs showing the number of tracked cells, track straightness and track speed of mDCs and T cells over time in response to a CCLI9 gradient or uniform $100 \mathrm{ng} \mathrm{mL}^{-1}$ CCL19 concentration. (B) Graphs showing the displacement of mDCs and T cells towards a gradient of CCL19. The displacement was analyzed by taking the average displacement of T cells toward a CCL19 gradient and subtracting the average displacement of T cells in the same direction in a uniform CCL19 concentration. Data are combined from three independent experiments and are presented as mean $+/$ SEM. Results were analyzed using multiple t-tests with the assumption that all populations have the same scatter and was corrected for multiple comparisons using the Holm-Sidak method. * $\mathrm{P}$-value $<0.05$, ${ }^{\star *} \mathrm{P}$-value $<0.01,{ }^{\star \star *} \mathrm{P}$-value $<0.001,{ }^{* \star \star *} \mathrm{P}$-value $<0.0001$

\section{Co-Culture of DCs and T Cells Changes T Cell Behavior but not DC Behavior}

When $\mathrm{T}$ cells were cultured separately very few cells migrated compared to the mDCs, suggesting some relative impairment of $\mathrm{T}$ cell migration. However, $\mathrm{T}$ cells cultured under the same conditions co-incubated with mDCs migrated $\sim 30$ times more frequently (Figure 4A), which refutes that notion. There is also an indication that there was an increase in displacement toward CCL19 (Figure 4B), although, because of donor variation, this did not reach statistical significance.

\section{DISCUSSION}

The data presented in this study showed that human polyclonal $\mathrm{T}$ cells, unlike mDCs, respond to a CCL19 gradient largely chemokinetically, showing a random walk with directional bias, and showing similarities to the response to a uniform CCL19 concentration. Previously published data showed that the human Jurkat T cell line, transfected with CCR7 to respond to CCL19, responded chemotacticly to a $100 \mathrm{nM} \mathrm{CCL19}$ gradient under experimental flow conditions (19). However, the authors of this study used a fibronectin-coated microfluidic device, and it has been reported that $\mathrm{T}$ lymphocytes can orientate their migration based on the direction of fluid flow during integrinmediated migration (20). Similarly, another study reported that $\mathrm{T}$ cells orientate towards $100 \mathrm{nM}$ CCL19 gradient (21) which is similar to what we see with the biased random walk. In our hands $\mathrm{T}$ cells in a CCL19 gradient showed an increase in displacement toward CCL19. This suggests that CCL19 induces a bias toward a gradient of CCL19, similar to a biased random walk, in T cells. It has been previously suggested that $\mathrm{T}$ cells can display a super diffuse random walk (Lévy walk) that emerges from an explorative process, informed movement, and interaction with the environment (22). These data are consistent with the behavior of $\mathrm{T}$ cells that use Lévy strategies to allow for optimal scanning of their environment for antigen (23).

When T cells were coincubated with mDCs there was a large increase in migrating $\mathrm{T}$ cells. The explanation is likely to be in the interactions of $\mathrm{T}$ cells with DCs. As visualized in the videos, $\mathrm{T}$ cells form brief contacts with DCs. This is consistent with the literature, showing that T cells briefly adhere to DCs, even in the 
absence of cognate antigen (24). This means that when a large population of DCs is introduced and is migrating directionally, $\mathrm{T}$ cell contacts with those cells will impart "momentum" in the same direction. The presence of $\mathrm{mDC}$ did not alter the 'random walk' of the $\mathrm{T}$ cells. In contrast, mDCs did not show any difference in their migration behavior whether tested in isolation or when co-incubated with T cells (Figure 4).

Our results suggest that $\mathrm{T}$ cells are programmed to respond differently to a gradient of CCL19 compared to DCs. They also indicate that $\mathrm{T}$ cells that are co-migrating with $\mathrm{mDCs}$ are not following pre-formed tracks made by the mDCs. This observation is further supported by the live-cell videos (Supplementary Videos 6 and 7) where T cells can be seen migrating ahead of the mDCs. It has been reported that mature DCs can produce CCL19 that induces migration and scanning in $\mathrm{T}$ cells (25). This could be the reason for the increased $\mathrm{T}$ cell migration observed in our assays, however, further study is necessary to confirm this, or if another mechanism is responsible for the increased $\mathrm{T}$ cell motility.

The random walk with a chemotactic bias that the $\mathrm{T}$ cells show toward a gradient of CCL19 observed using our live-cell assay fits with models that have been previously generated (26). Computational modelling of the random walk has shown that this movement pattern would be more efficient in activating $\mathrm{T}$ cells than chemotaxis alone (27) as this enables efficient scanning of antigen-presenting cells in lymphoid tissues.

It seems likely that $\mathrm{T}$ cells' ultimate paths will be determined by their inherent explorative behavior combined with their interactions with cells and molecules in their environment, given that they constantly scan and form transient cell-cell connections with professional antigen-presenting cells (28), that themselves can produce cytokines that stimulate $\mathrm{T}$ cell migration $(25,29-31)$.

Using the assay presented here it was possible to show a clear difference in migration behavior between $\mathrm{mDCs}$ and $\mathrm{T}$ cells. The $\mathrm{T}$ cell-specific motility patterns we observed highlight the exploratory behavior of $\mathrm{T}$ cells under CCR7 signaling that is likely to be crucial in generating optimal immune responses.

\section{REFERENCES}

1. Comerford I, Harata-Lee Y, Bunting MD, Gregor C, Kara EE, McColl SR. A myriad of functions and complex regulation of the CCR7/CCL19/CCL21 chemokine axis in the adaptive immune system. Cytokine Growth Factor Rev (2013) 24:269-83. doi: 10.1016/j.cytogfr.2013.03.001

2. Förster R, Davalos-Misslitz AC, Rot A. CCR7 and its ligands: balancing immunity and tolerance. Nat Rev Immunol (2008) 8:362-71. doi: 10.1038/nri2297

3. Worbs T, Mempel TR, Bölter J, Von Andrian UH, Förster R. CCR7 ligands stimulate the intranodal motility of T lymphocytes in vivo. J Exp Med (2007) 204:489-95. doi: 10.1084/jem.20061706

4. Bogle G, Dunbar PR. Simulating T-cell motility in the lymph node paracortex with a packed lattice geometry. Immunol Cell Biol (2008) 86(8):676-87. doi: $10.1038 /$ icb. 2008.60

5. Pujic Z, Mortimer D, Feldner J, Goodhill G. Assays for Eukaryotic Cell Chemotaxis. Comb Chem High Throughput Screen (2009) 12:580-8. doi: $10.2174 / 138620709788681952$

6. Nelson RD, Quie PG, Simmons RL. Chemotaxis Under Agarose: A New and Simple Method for Measuring Chemotaxis and Spontaneous Migration of

\section{DATA AVAILABILITY STATEMENT}

The raw data supporting the conclusions of this article will be made available by the authors, without undue reservation.

\section{ETHICS STATEMENT}

The studies involving human participants were reviewed and approved by University of Auckland Human Participants Ethics Committee (UAHPEC). The patients/participants provided their written informed consent to participate in this study.

\section{AUTHOR CONTRIBUTIONS}

$\mathrm{NB}$ and RD obtained funding for the research. EL, NB, and RD designed the experiments. EL carried out and analyzed all the experiments. HS obtained ethics for all work with primary human blood cells. EL, HS, and RD wrote the manuscript. All authors contributed to the article and approved the submitted version.

\section{FUNDING}

This research was supported by a Marsden Grant from the Royal Society of New Zealand (to NB and RD), project ID: 15-UOA-218, and The Maurice Wilkins Centre For Molecular Biodiscovery.

\section{SUPPLEMENTARY MATERIAL}

The Supplementary Material for this article can be found online at: https://www.frontiersin.org/articles/10.3389/fimmu.2021. 628090/full\#supplementary-material

Human Polymorphonuclear Leukocytes and Monocytes. J Immunol (1975) 115:1650-6.

7. Krummel MF, Friedman RS, Jacobelli J. Modes and mechanisms of T cell motility: Roles for confinement and Myosin-IIA. Curr Opin Cell Biol (2014) 30:9-16. doi: 10.1016/j.ceb.2014.05.003

8. Lämmermann T, Bader BL, Monkley SJ, Worbs T, Wedlich-Söldner R, Hirsch K, et al. Rapid leukocyte migration by integrin-independent flowing and squeezing. Nature (2008) 453:51-5. doi: 10.1038/nature06887

9. Friedl P, Entschladen F, Conrad C, Niggemann B, Zanker KS. CD4+ T lymphocytes migrating in three-dimensional collagen lattices lack focal adhesions and utilize??1 integrin-independent strategies for polarization, interaction with collagen fibers and locomotion. Eur J Immunol (1998) 28:2331-43. doi: 10.1002/(SICI)1521-4141(199808)28:08\&

10. Heit B, Kubes P. Measuring Chemotaxis and Chemokinesis: The UnderAgarose Cell Migration Assay. Sci Signal (2003) 2003:pl5-5. doi: 10.1126/ stke.2003.170.pl5

11. Vargas P, Maiuri P, Bretou M, Sáez PJ, Pierobon P, Maurin M, et al. Innate control of actin nucleation determines two distinct migration behaviours in dendritic cells. Nat Cell Biol (2016) 18:43-53. doi: 10.1038/ncb3284 
12. Sixt M, Lämmermann T. In vitro analysis of chemotactic leukocyte migration in 3D environments. Methods Mol Biol (2011) 769:149-65. doi: 10.1007/978$1-61779-207-6$

13. Visweshwaran SP, Maritzen T. A simple 3D cellular chemotaxis assay and analysis work flow suitable for a wide range of migrating cells. MethodsX (2019) 6:2807-21. doi: 10.1016/j.mex.2019.11.001

14. Barmore AJ, Castex SM, Gouletas BA, Griffith AJ, Slater W, Muelder NG, et al. Transferring the C-terminus of the chemokine CCL21 to CCL19 confers enhanced heparin binding. Biochem Biophys Res Commun (2016) 477:602-6. doi: 10.1016/j.bbrc.2016.06.098

15. Lehner M, Morhart P, Stilper A, Holter W. Functional characterization of monocyte-derived dendritic cells generated under serumfree culture conditions. Immunol Lett (2005) 99:209-16. doi: 10.1016/j.imlet.2005.02.016

16. Loef EJ, Brooks AES, Lorenz N, Birch NP, Dunbar PR. Neuroserpin regulates human $\mathrm{T}$ cell-T cell interactions and proliferation through inhibition of tissue plasminogen activator. J Leukoc Biol (2019) 107(1):145-58. doi: 10.1002/ JLB.2A1019-098RR

17. Lorenz N, Loef EJ, Verdon DJ, Chen C-JJ, Mansell CJ, Angel CE, et al. Human $\mathrm{T}$ cell activation induces synaptic translocation and alters expression of the serine protease inhibitor neuroserpin and its target protease. J Leukoc Biol (2015) 97:1-12. doi: 10.1189/jlb.1A0814-392R

18. Lorenz N, Loef EJ, Kelch ID, Verdon DJ, Black MM, Middleditch MJ, et al. Plasmin and regulators of plasmin activity control the migratory capacity and adhesion of human $\mathrm{T}$ cells and dendritic cells by regulating cleavage of the chemokine CCL21. Immunol Cell Biol (2016) 94:955-63. doi: 10.1038/ icb. 2016.56

19. Wu X, Wu J, Li H, Legler DF, Marshall AJ, Lin F. Analysis of CCR7 mediated $\mathrm{T}$ cell transfectant migration using a micro fluidic gradient generator. J Immunol Methods (2015) 419:9-17. doi: 10.1016/j.jim.2015.02.008

20. Valignat M, Theodoly O, Gucciardi A, Hogg N, Lellouch AC. T Lymphocytes Orient against the Direction of Fluid Flow during LFA-1-Mediated Migration. Biophysj (2013) 104:322-31. doi: 10.1016/j.bpj.2012.12.007

21. Nandagopal S, Wu D, Lin F. Combinatorial guidance by CCR7 ligands for T lymphocytes migration in co-existing chemokine fields. PloS One (2011) 6(3): e18183. doi: 10.1371/journal.pone.0018183

22. Krummel MF, Bartumeus F, Gérard A. T cell migration, search strategies and mechanisms. Nat Rev Immunol (2016) 16:193-201. doi: 10.1038/nri.2015.16

23. Harris TH, Banigan EJ, Christian DA, Konradt C, Wojno EDT, Norose K, et al. Generalized Lévy walks and the role of chemokines in migration of effector CD8 + T cells. Nature (2012) 486:545-8. doi: 10.1038/nature11098
24. Miller MJ, Hejazi AS, Wei SH, Cahalan MD, Parker I. T cell repertoire scanning is promoted by dynamic dendritic cell behavior and random $\mathrm{T}$ cell motility in the lymph node. Proc Natl Acad Sci U S A (2004) 101:998-1003. doi: $10.1073 /$ pnas.0306407101

25. Kaiser A, Donnadieu E, Trautmann A, Nardin A, Kaiser A, Donnadieu E, et al. CC Chemokine Ligand 19 Secreted by Mature Dendritic Cells to Rare Cognate Antigen. J Immunol (2005) 175:2349-56. doi: 10.4049/ jimmunol.175.4.2349

26. Bogle G, Dunbar PR. On-Lattice Simulation of T Cell Motility, Chemotaxis, and Trafficking in the Lymph Node Paracortex. PloS One (2012) 7(9):e45258. doi: 10.1371/journal.pone.0045258

27. Riggs T, Walts A, Perry N, Bickle L, Lynch JN, Myers A, et al. A comparison of random vs . chemotaxis-driven contacts of $\mathrm{T}$ cells with dendritic cells during repertoire scanning. J Theor Biol (2008) 250:732-51. doi: 10.1016/ j.jtbi.2007.10.015

28. Dustin ML. T-cell activation through immunological synapses and kinapses. Immunol Rev (2008) 221:77-89. doi: 10.1111/j.1600-065X.2008.00589.x

29. Castellino F, Huang AY, Altan-Bonnet G, Stoll S, Scheinecker C, Germain RN. Chemokines enhance immunity by guiding naive CD8+ T cells to sites of CD4+ T cell-dendritic cell interaction. Nature (2006) 440:890-5. doi: 10.1038/ nature04651

30. Penna G, Vulcano M, Roncari A, Facchetti F, Sozzani S, Adorini L. Cutting Edge: Differential Chemokine Production by Myeloid and Plasmacytoid Dendritic Cells. J Immunol (2002) 169:6673-6. doi: 10.4049/ jimmunol.169.12.6673

31. Beaty SR, Rose CE, Sung SJ. Diverse and Potent Chemokine Production by Lung CD11b high Dendritic Cells in Homeostasis and in Allergic Lung Inflammation. J Immunol (2007) 178:1882-95. doi: 10.4049/ jimmunol.178.3.1882

Conflict of Interest: The authors declare that the research was conducted in the absence of any commercial or financial relationships that could be construed as a potential conflict of interest.

Copyright (c) 2021 Loef, Sheppard, Birch and Dunbar. This is an open-access article distributed under the terms of the Creative Commons Attribution License (CC BY). The use, distribution or reproduction in other forums is permitted, provided the original author(s) and the copyright owner(s) are credited and that the original publication in this journal is cited, in accordance with accepted academic practice. No use, distribution or reproduction is permitted which does not comply with these terms. 